\title{
CORRIGENDUM
}

\section{Dietary vitamin A intake and bone health in the elderly: the Rotterdam Study}

EAL de Jonge, JC Kiefte-de Jong, N Campos-Obando, L Booij, OH Franco, A Hofman, AG Uitterlinden, F Rivadeneira and MC Zillikens

European Journal of Clinical Nutrition (2015) 69, 1375; doi:10.1038/ejcn.2015.187

Correction to: European Journal of Clinical Nutrition (2015) 69, 1360-1368; doi:10.1038/ejcn.2015.154; published online 16 September 2015

Since the publication of this article, the authors have noticed an error in Figure 4. The corrected figure is displayed below, and has also been corrected in the article pdf and html.

The authors apologize for any inconvenience caused.
Associations between intake of total vitamin A and BMD in strata of vitamin D intake

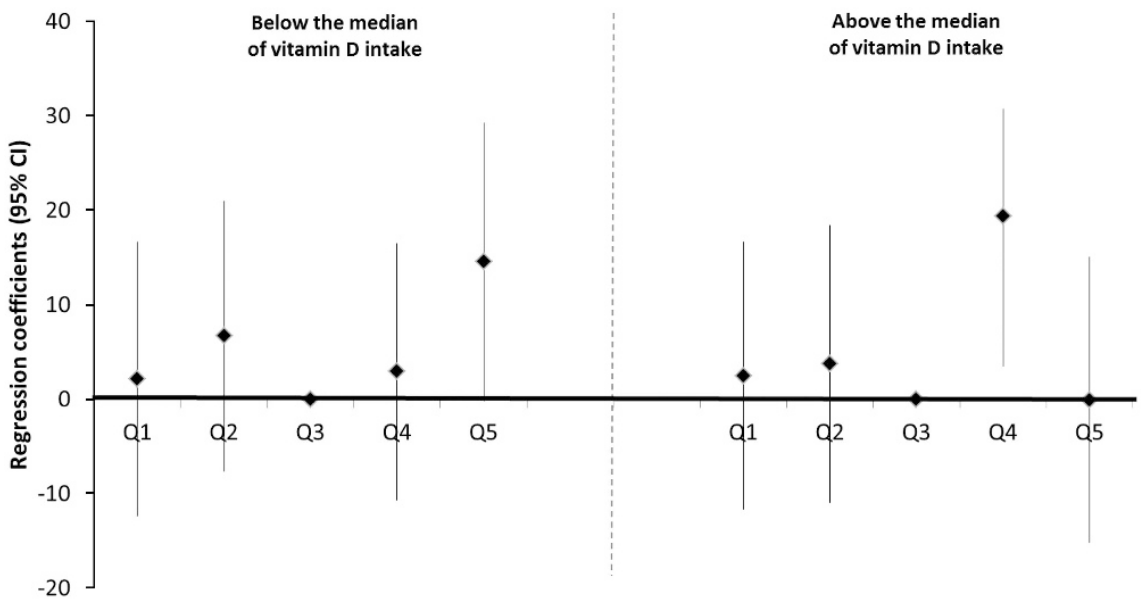

b

Associations between intake of beta-carotene and BMD in strata of vitamin D intake

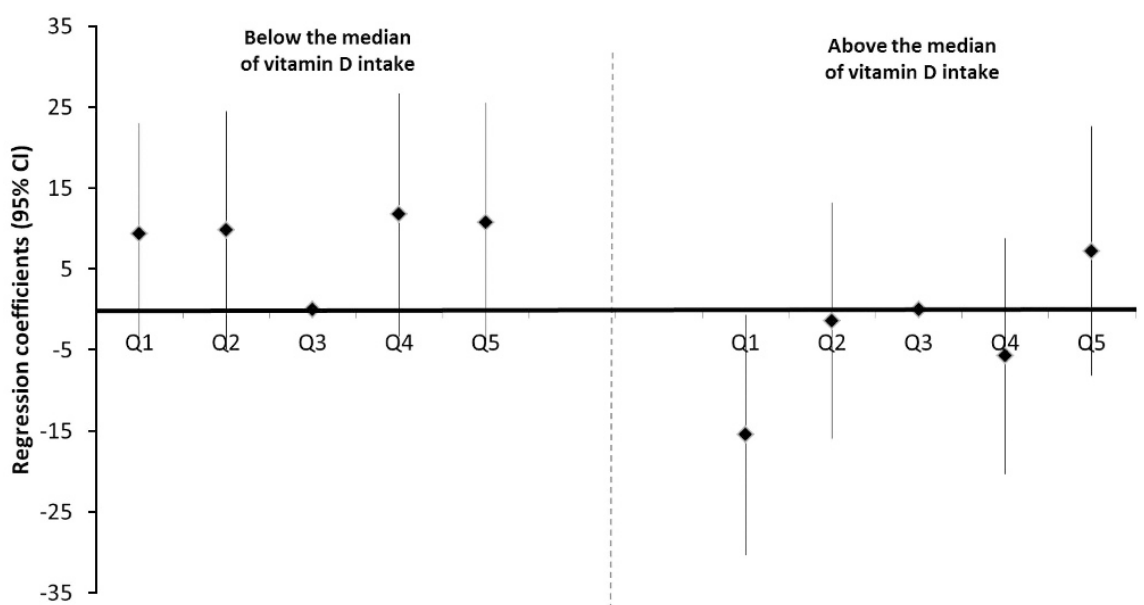

Figure 4. Associations between energy-adjusted dietary intake of total vitamin A (a) or beta-carotene (b) and BMD in strata of dietary vitamin D intake (above or below the median of $3.2 \mu \mathrm{g} /$ day, using model 3. Model 3: adjusted for age, sex, calcium intake, smoking, disability index, net income, highest education level, physical activity, alcohol intake, BMI and for women only HRT use, age at menopause. Abbreviations: HRT, hormone replacement therapy; BMI, body mass index; BMD, bone mineral density. 